\title{
Technological Innovation of Unpowered Operational Gearing
}

\author{
Shu-Lung Wang* \\ Department of Mechanical Engineering \\ Taoyuan Innovation Institute of Technology \\ NO.414,Sec.3, Jhongshan E. Rd., Jhongli District, \\ Taoyuan City, 32091 Taiwan (R.O.C.) \\ wzl@tiit.edu.tw
}

\author{
Ay Su, Yi-Feng Chang \\ Department of Mechanical Engineering \\ Yuan Ze University \\ NO.135 Yuan-Tung Rd., Jhongli District, Taoyuan City, \\ 32003 Taiwan (R.O.C.) \\ no4704083@yahoo.com.tw, \\ meaysu@saturn.yzu.edu.tw
}

\author{
Jui-Yang Wang \\ Department of Information Management \\ National central University of Science and Technology \\ NO.300, zhong Da. Rd., Jhongli District, Taoyuan City, 32001 Taiwan (R.O.C.) \\ tom_yrtoo135@yahoo.com.tw
}

\begin{abstract}
As industrial structures rapidly change and international competitive pressure becomes increasingly large, Taiwan's industries face a bottleneck of structural transformation and technological innovation. In addition, as the international oil price increases, the price of electricity goes up and production costs are continuously raised. As the European debt crisis continues to expand the deterioration of the global economy, how to reduce costs, improve the industrial competitiveness, rapidly react to market demands, improve customer service satisfaction, etc., to take the lead in global competition has become a priority. This study discussed the reactive force and operation of unpowered gear machines, including power generating parts and work parts. Therefore, in the operation process, there must be the application and receipt of [power and force]. This case study is used reactive force without the use of electricity or electrical equipment to work, transport, and generate the effects of delivery. Since unpowered devices are used to implement the normal operations of work machines, according to empirical processes, the basis of automation technology innovation can be provided, which feature the effects of energy conservation and time-saving.
\end{abstract}

Keywords - Unpowered gearing, Technological innovation of automation

\section{INTRODUCTION}

The industrial revolution in 18-19th century created the modern mode of machine use, and production lines were formed, which further improved productivity, and allowed The development process of the global industrial production mode can be divided into three phases, manual production during the [Traditional Theory Period], mass production of a few types during the [Correction Theory], and small amount production of multiple types in the [New Theory], as seen in Table 1.
TABle I. DeVelopment Process of Production Mode

\begin{tabular}{|l|l|c|c|}
\hline Phase & Traditional Theory & Correction Theory & New Theory \\
\hline School & Heritage Management & $\begin{array}{c}\text { Behavioral School } \\
\text { Scientific Management }\end{array}$ & $\begin{array}{c}\text { Systems School } \\
\text { Contingency School }\end{array}$ \\
\hline
\end{tabular}

Manual operation was a time of master craftsman, and uneven and unstable quality due to individual craftsmanship allowed immediate pickup and fast delivery. After the industrial revolution, according to the scientific management rules of Taylor, in order to change the work efficiency of laborers, Taylor carefully studied every movement and designed the best work processes to the maximum work efficiency.

\section{LITERATURE BACKGROUND}

Taiwan has no mineral resources of crude oil, all the variety of manufacturing industries constitute the country's major economic lifeline [1]. We can say that all of the small-tomedium enterprises create a Taiwan economic miracle, laying out the Newly Industrial Economics in Asia. In recent years, a large number of relocation happen to industrial; mainland China has become the factory of the globe. With the rising awareness of labor right and the government's strictness in environmental protection in Taiwan, all kinds of enterprises have faced severe challenges. Only by promoting downstream supply chain vertical integration, improving the manufacturing process, and demanding high-quality cost control, can enterprises pursuit higher profits and face various challenges to demonstrate competitive advantages. 
Biped robot in modern robotics research is an important direction [2]. However, the multi-degree of freedom connecting rod mechanism results from the balance problem when biped robot moves. Therefore, the biped robot gait design has been an important issue on the biped robot.

\section{RESEARCH PURPOSE}

Based on the above industrial development background, this study focused on the technological innovation of unpowered delivery and handling systems, which may reduce operational costs, and assist in energy conservation and carbon reduction in the production of technological products.

This study has three objectives:

1) How does equipment manufactured industrial production reduce power consumption?

2) How to reduce power consumption when handling and delivering heavy and large objects?

3) The design of technological innovation of aggregate unpowered mechanical gearing that works independently.

\section{RESEARCH METHOD}

Regarding relevant research and thesis about easy automation and unpowered equipment in Taiwan, this study focuses on the case of Kuozui Motors and constructs positive experiences of the practical use of unpowered equipment in production.

\section{RESULTS AND DisCUSSION}

CAMRY ROCKER S/A handling work process is, as shown in Fig. 1. After CAMRY ROCKER S/A finishes, use Auto Guide Vehicle (AGV) to feed secondary projects, as shown in Fig. 2 and Table II.

Remove Item 7 and operate with both hands; handling of items using AGV takes 9 seconds/item; the use of AGV causes high equipment investment, and high equipment failure rate and collision between AGV and the items. Thoughts for improvement are designed, as follows:

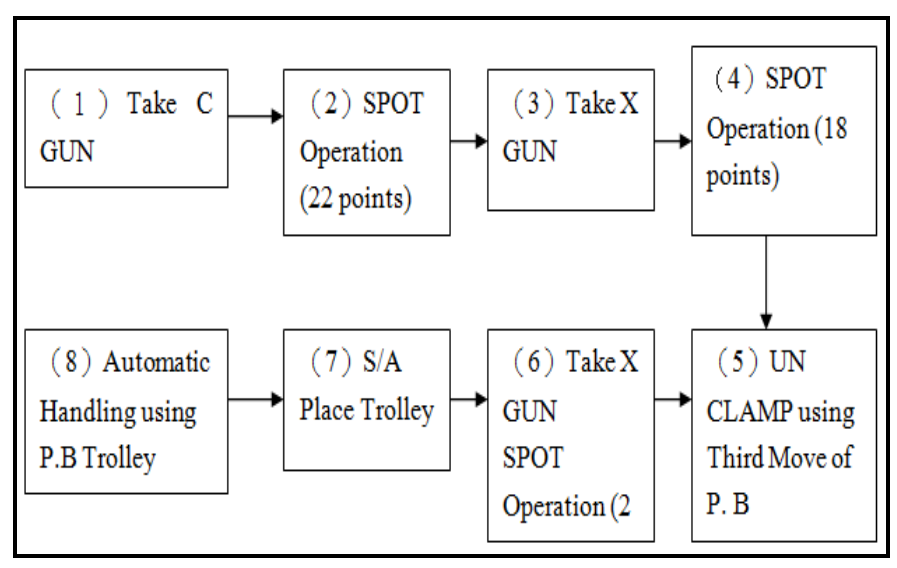

Fig. 1. S/A handling process

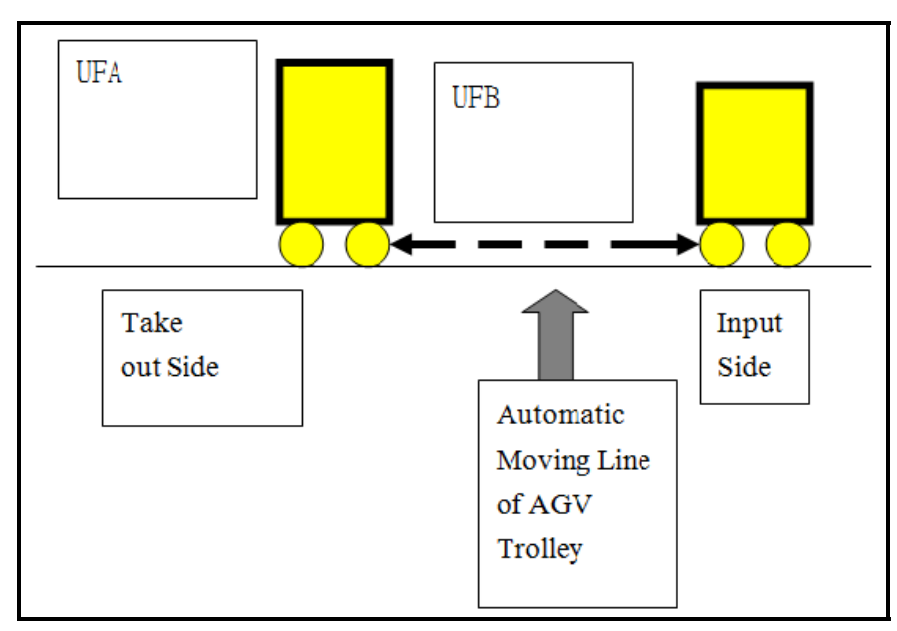

Fig. 2. AGV process

TABLE II. STATISTICS TABLE OF SECONDS CONSUMED IN STANDARD OPERATION PROJECTS

\begin{tabular}{|c|c|c|c|c|c|c|c|c|c|c|c|}
\hline Subject & \multicolumn{4}{|c|}{ Item SET } & \multicolumn{3}{|c|}{ Item Takeout } & $\begin{array}{l}\text { Walking } \\
\text { with } \\
\text { Bare }\end{array}$ & \multicolumn{3}{|c|}{ Walking Haulage } \\
\hline $\begin{array}{l}\text { Operation } \\
\text { Content }\end{array}$ & $\begin{array}{l}\text { Lifting } \\
\text { Device of } \\
\text { Large } \\
\text { Objects }\end{array}$ & $\begin{array}{c}\text { Medium } \\
\text { Objects } \\
\text { S/A }\end{array}$ & $\begin{array}{l}\text { Change of } \\
\text { Hand in } \\
\text { Handling } \\
\text { Medium } \\
\text { Object }\end{array}$ & $\begin{array}{l}\text { Small } \\
\text { Objects }\end{array}$ & $\begin{array}{l}\text { Liffing } \\
\text { Device } \\
\text { of } \\
\text { Large } \\
\text { Objects }\end{array}$ & $\begin{array}{l}\text { Change of } \\
\text { Hand in } \\
\text { Handling } \\
\text { Medium } \\
\text { Object }\end{array}$ & $\begin{array}{c}\text { Small } \\
\text { Objects }\end{array}$ & $\begin{array}{l}\text { Walking } \\
\text { with } \\
\text { Bare } \\
\text { Hands }\end{array}$ & $\begin{array}{l}\text { Lifting } \\
\text { Device } \\
\text { of } \\
\text { Large } \\
\text { Objects }\end{array}$ & $\begin{array}{l}\text { Change of } \\
\text { Hand in } \\
\text { Handing } \\
\text { Medium } \\
\text { Object }\end{array}$ & $\begin{array}{l}\text { Small } \\
\text { Objects }\end{array}$ \\
\hline Unit & 1 piece & 1 piece & 1 piece & 1 piece & 1 piece & 1 piece & 1 piece & 3 steps & 3 steps & 3 steps & 3 steps \\
\hline TMC & 12 & 7 & 5 & 2 & 15 & 7 & 7 & 2 & 2 & 2 & 2 \\
\hline $\begin{array}{l}\text { Actual } \\
\text { Measurem } \\
\text { ent }\end{array}$ & 15 & 7 & 5 & 3 & 12 & 7 & 3 & 2 & 2 & 2 & 2 \\
\hline AGV & & & & & & 9 & & & & & \\
\hline
\end{tabular}

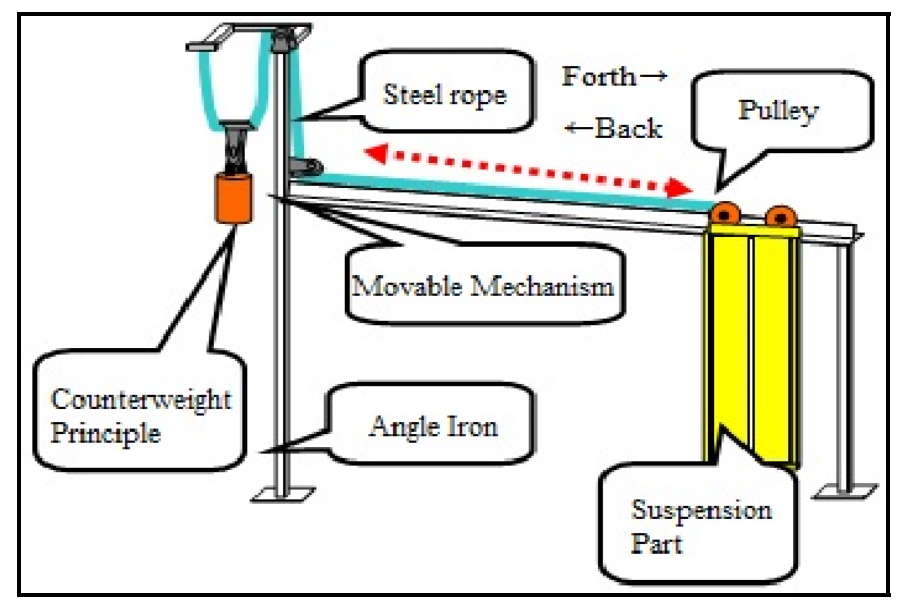

Fig. 3. Unpowered automatic handling design 
As shown in Fig. 3, produce carriage: a movable mechanism allows reciprocal operation; apply counterweight mechanism and use pulley mechanism toward the lighter direction to hang the item and achieve an unpowered mechanism; no power or powered mechanism is required to realize the objective of cost reduction, as well as energy consumption and carbon reduction.

\section{CONCLUSION AND SUGGESTIONS}

This study discussed the case of Kuozui Motors, extracted the data of actually consumed time (in seconds) of unpowered equipment, and achieved power consumption and time saving.as show Table III.

TABLE III. STATISTICS TABLE OF VARIOUS OPERATION CONTENT TOTAL CONSUMED TIME

\begin{tabular}{|c|c|c|c|c|}
\hline \multirow{2}{*}{ Operation Lane } & \multirow{2}{*}{ Operation Content } & \multicolumn{3}{|c|}{ Time } \\
\hline & & Manual & Automatic & Walk \\
\hline \multirow{9}{*}{11} & Take C GUN & 2 & & \\
\hline & SPOT Operation ( 22 points) & 66 & & \\
\hline & & & & \\
\hline & Take X GUN & 2 & & \\
\hline & SPOT Operation (18 points) & 51 & & \\
\hline & & & & \\
\hline & UN CLAMP using P.B Third Move & 2 & & \\
\hline & Take X GUN SPOT Operation (2 points) & 8 & & \\
\hline & & & & 2 \\
\hline \multirow{4}{*}{12} & S/A Place Trolley & 6 & & \\
\hline & & & & \\
\hline & Automatic Handling using Switch Trolley & 0 & & \\
\hline & & & & 2 \\
\hline \multicolumn{2}{|r|}{ Subtotal } & 137 & & 4 \\
\hline \multicolumn{2}{|r|}{ Total } & & & 141 \\
\hline
\end{tabular}

1. The strengthening of corporate competitiveness cannot be limited to improvement of original operation procedures, meaning enterprises must develop new products at faster speeds and adopt new operational patterns.

2. Active research and proposal of improvement methods and strategies to improve comprehensive handling quality.

3. Careful observation and checking of operations to determine designs corrections and improvements.

4. For long distance delivery, adopt multiple point hanging or dual pulley mechanism to maintain smooth, continuous, time-saving operations.

\section{REFERENCES}

[1] K.T. Hsieh, Simulation of Automatic Material Handling System in a Flexible Manufacturing System Department of Engineering Science, National Cheng Kung University, 2008.

[2] C.H. Chien, Energy Efficiency Analysis of Passive Solar Chimney - A Case Study on the International Conference Hall of the Magic School of Green Technology Graduate Institute of Architecture, National Cheng Kung University, 2009.
[3] I.H. Chen, The arch unpowered machinery improvement, and the walking gaits design for biped robots Graduate Institute of Electrical Engineering, National Chung Cheng University, 2013.

[4] P.H. Yang, A Study of the Warning System for Automated Material Handling Systems Extended Education on Information and Electrical Engineering, Master Program. 2013.

[5] C.Y. Tang, The study of the Wheelchair with Manual Step-climbing Function Department of Mechanical Engineering national united University Master Program 2012. 